\title{
PROFISSIONALIDADE DOCENTE: UM OLHAR SOBRE A CONDIÇÃO DE TRABALHO DO FORMADOR DO INSTITUTO DE FORMAÇÃO DE PROFESSORES DE CHONGOENE
}

\author{
Isabel Vasco Mamude \\ Mataruca
}

Universidade Eduardo Mondlane, Moçambique. isabelmataruca@gmail.com

\begin{abstract}
Resumo. O presente artigo tem como objectivo investigar a construção da profissionalidade dos formadores de professores primários e de educadores de adultos do Instituto de Formação de Professores de Chongoene, buscando compreender os diversos elementos que contribuem no processo de formação docente, a partir de três questionamentos: qual é o perfil do formador de professores primários e de educadores de adultos no Instituto de Formação de Professores de Chongoene? Que desafios esses profissionais enfrentam no processo de ensino e aprendizagem? E quais são as percepções, expectativas e motivações dos formadores do Instituto de Formação de Professores de Chongoene sobre o novo modelo de formação de professores e educadores de adultos? Para a concretização dos objectivos definidos, este estudo recorreu ao paradigma interpretativista $\mathrm{O}$ estudo assumiu a forma de um estudo de caso múltiplo, integrando 16 participantes, considerando-se cada sujeito um caso ou unidade de análise. As especificidades da profissionalidade docente dos participantes deste estudo emergiram nos dados e constituíram-se em dez categorias de análise às suas percepções, expectativas e motivações e revela-se pela constante mobilização de saberes diversos para identificar e resolver problemas quotidianos marcados pela incerteza, imbuídos por uma forte motivação intrínseca.
\end{abstract}

Palavras-chave: Profissionalidade Docente; Formação de Professores; Competência; Habilidades; Prática Docente.

\section{PROFESSIONALISM IN TEACHING: A LOOK AT THE CONDITION OF THE PRIMARY TEACHER TRAINERS AND ADULT EDUCATORS AT THE CHONGOENE TEACHER TRAINING INSTITUTE}

Abstract. This article aims to investigate the construction of the professionalism of primary teacher trainers and adult educators at the Chongoene Teacher Training Institute, seeking to understand the various elements that contribute to the teacher training process, based on three questions: What is the profile of the primary teacher trainer and adult educators at the Chongoene Teacher Training Institute? What challenges do these professionals face in the teaching and learning process? And what are the perceptions, expectations and motivations of the trainers of the Chongoene Teacher Training Institute about the new model for training teachers and adult educators? In order to achieve the defined objectives, this study used the interpretive paradigm. The study took the form of a multiple case study, comprising 16 participants, of whom each was considered a case or unit of analysis. The specificities of the professionalism in teaching of the participants emerged in the data and constituted ten categories of analysis to their perceptions, expectations and motivations and is revealed by the constant mobilization of diverse knowledge for identify and effort to solve everyday problems marked by uncertainty, imbued with a strong intrinsic motivation.

Keywords: Professionalism in Teaching; Teacher Education; Competence; Skills; Teaching Practice. 


\section{INTRODUÇÃO}

A profissionalidade docente é um termo socialmente construído que vem se destacando nas pesquisas e nas políticas educacionais internacionais a partir dos anos 1990 (Roldão, 2005). Contudo, Pançardes (2010), citado em Gorzoni e Davis (2017, p.4), "ao investigar a especificidade da profissão docente, encontrou o que interpretou como falta de consenso entre os autores quanto aos aspectos envolvidos no tema profissionalidade docente".

De facto, vários autores (Ambrosetti \& Almeida, 2009; André \& Placco, 2007; Contreras, 2012; Gimeno Sacristán, 1995; Libâneo, 2015; Morgado, 2011; Ramalho, Nuñez, \& Gauthier, 2004; Roldão, 2005) apresentam diferentes posicionamentos na abordagem do tema da profissionalidade.

Contudo, neste artigo optámos pela posição defendida por Gimeno Sacristán (1995) por considerar que apresenta elementos que mais se aproximam ao nosso tema. Para este autor, citado em Gorzoni e Davis (2017, p.6), “a profissionalidade se dá na relação dialética entre os diferentes contextos práticos e os conhecimentos, as habilidades ]...[ e está ligada a um tipo de desempenho e de conhecimento específicos".

Concordando com Gorzoni e Davis (2017, p.6), "a profissionalidade está baseada nos saberes e no saber-fazer do professor, traduzidos pela ação de ensinar, orientar o estudo do aluno individualmente e/ou em grupo, regular as relações em sala de aula, preparar materiais, avaliar, organizar espaços e atividades".

Neste contexto, no presente trabalho, o objectivo é investigar a construção da profissionalidade dos formadores de professores primários e de educadores de adultos do Instituto de Formação de Professores (IFP) de Chongoene, visando compreender os diversos elementos que contribuem no processo de formação docente, a partir de três questões: qual é o perfil do formador de professores primários e de educadores de adultos do IFP de Chongoene? Que desafios esses profissionais enfrentam no processo de ensino e aprendizagem? E quais são as percepções, expectativas e motivações desses formadores sobre o novo modelo de formação de professores primários e de educadores de adultos? 
Em outras palavras, procurámos neste trabalho analisar a actuação do formador do IFP de Chongoene em duas dimensões inter-relacionadas: institucional e pedagógica.

"A dimensão institucional está vinculada aos processos formativos e às práticas escolares. A dimensão pedagógica relaciona-se às situações de ensino e à relação que o professor estabelece com os alunos e com o conhecimento" (Gorzoni \& Davis, 2017, p.9).

\section{CONTEXTUALIZAÇÃO}

Este estudo teve lugar no IFP de Chongoene, criado por despacho oㅡ 263/GM/MINEDH/2015, de 09 de Outubro, do Ministro da Educação e Desenvolvimento Humano, como resultado da extinção dos Institutos de Educadores de Adultos (IFEAs) criados pelo Diploma Ministerial nำ180/2010, de 03 de Novembro.

A ideia da extinção dos IFEAs prende-se com o objectivo de formar apenas professores dotados de uma formação integrada por saberes plurais construídos, capazes de trabalhar com as pessoas de todas as idades.

A integração dos IFEAs na rede nacional dos IFPs e a adopção de um novo modelo de formação de professores $12^{\underline{a}}+3$ cria novos desafios institucionais e pedagógicos para os formadores do profissional de ensino que se pretende, na condução do processo de ensino e aprendizagem. Esta nova realidade na formação de professores propiciou a condução deste estudo cujo enfoque é a construção da profissionalidade dos formadores de professores primários e de educadores de adultos do IFP de Chongoene. "Pensar a profissionalidade docente significa pensar em como os docentes se situam e agem no contexto de trabalho, forjando uma identidade que afeta e é afetada por esse contexto" (Gorzoni \& Davis, 2017, p.10).

\section{REFERENCIAL TEÓRICO}

Conhecer o modo como os adultos constroem, elaboram e dão significado aos seus conhecimentos ajuda o formador a orientar as suas práticas pedagógicas, respeitando as subjectividades dos aprendentes com seus níveis, ritmos e suas singularidades. Assim, o estudo socorre-se das contribuições de Malcolm Knowles (2005) com os princípios da andragogia e Paulo Freire (2013) sobre a dialogicidade no processo de aprendizagem de adultos. Teixeira (2006), citado em Santos (2006) enumera os seguintes princípios da aprendizagem de adultos: (i) a aprendizagem deve ser centralizada em problemas (ii) a 
aprendizagem deve ser centralizada em experiências (iii) a experiência deve ser significativa para o estudante (iv) o aprendiz deve ter liberdade de analisar a experiência (v) as metas e a pesquisa devem ser fixadas e executadas pelo aluno (vi) o aluno deve receber o "feed-back" sobre o seu progresso em relação às metas. De acordo com Santos (2006) citando Teixeira

(2006), tais princípios representam um conjunto de directrizes para a obtenção de um ambiente de aprendizagem de adultos efetiva.

Por outro lado, a dialogicidade de Freire (2013) consiste na problematização do conhecimento na relação que tem com a realidade. O conhecimento provém da realidade e incide sobre ela por forma a melhor percebê-la, explicá-la e transformá-la. Neste contexto, procura-se aqui explorar os princípios da aprendizagem dialógica tomando como base teórica os estudos de Freire (2013) com a sua dialogicidade e os estudos de Habermas (1984) com a sua teoria da Acção Comunicativa, que se baseia na procura de consensos entre formadores e aprendentes com vista ao entendimento mútuo, livre de qualquer tipo de coação.

\section{METODOLOGIA}

Nesta pesquisa recorreu-se ao paradigma interpretativista, seguindo uma abordagem qualitativa buscando significados, motivações, aspirações, crenças, valores e atitudes dos formadores de professores primários e de educadores de adultos no seu processo de inserção profissional e de formação docente.

Para Creswell (2007), os procedimentos da pesquisa qualitativa são caracterizados como indutivos, emergentes e determinados pela experiência do pesquisador na recolha e análise de dados. Assim, a presente pesquisa adopta o método indutivo e tendo em conta os objectivos da pesquisa, que é exploratória e descritiva, tendo privilegiado a entrevista semi- estruturada. Um dos aspectos característicos deste estudo foi a importância que a pesquisadora atribuíu à perspectiva dos formadores de professores primários e de educadores de adultos, a qual foi captada essencialmente a partir do seu discurso. Neste sentido, a entrevista teve um papel importante a desempenhar, já que ela foi utilizada para recolher dados descritivos na linguagem do próprio sujeito, permitindo à pesquisadora desenvolver intuitivamente uma ideia sobre a maneira como o sujeito interpretava aspectos do processo de ensino e aprendizagem. Foram feitas perguntas abertas, para 
permitir aos entrevistados expressar livremente as suas ideias, sentimentos e emoções, o que deu para perceber que alguns participantes falavam com paixão, muitas vezes sem esconder a fé com que defendem seus ideais e demonstrando reviver as emoções experimentadas, ilustravam o que diziam com situações que haviam vivenciado, o que facilitou que se cumprisse com o recomendado por Stake (2009, p. 82), segundo o qual, "O propósito para a maior parte dos entrevistadores não é obter simples respostas de sim ou não, mas a descrição de um episódio, uma ligação entre factos, uma explicação".

O estudo assumiu a forma de um estudo de caso múltiplo, integrando 16 participantes, considerando-se cada sujeito um caso ou unidade de análise (Miles \& Huberman, 1994). $\mathrm{Na}$ acepção de Stake (2009), tratou-se de um estudo de caso colectivo, porque procurouse compreender os diversos elementos que contribuem no processo de formação docente através do estudo da prática de diversos formadores (um formador, um caso).

Cada participante foi informado sobre os objectivos da entrevista, bem como da liberdade de responder ou não às questões que Ihes foram colocadas e, com a autorização dos mesmos, foram gravadas as entrevistas em suporte magnético e posteriormente feita a transcrição codificada de acordo com as normas para transcrição de entrevistas gravadas, retiradas de Preti (1999).

Seguiu-se o modelo misto de análise de conteúdo, tendo iniciado o processo com a definição de categorias prévias. Foram recortados os textos das entrevistas em unidades de contexto que "servem de unidade de compreensão para codificar a unidade de registo e corresponde ao segmento da mensagem, cujas dimensões (superiores as da unidade de registo) são óptimas para que se possa compreender a significação exacta da unidade de registo" (Bardin, 1979, p. 107), e unidades de registo que "é a unidade de significação a codificar e corresponde ao segmento de conteúdo a considerar como unidade base, visando a categorização e a contagem frequencial" (Bardin, 1979, p. 104).

\section{RESULTADOS}

No processo de recolha de dados, efectuaram-se entrevistas envolvendo um total de 16 participantes, dos quais $31.25 \%$ são do sexo feminino, distribuídos de acordo com a Tabela

1. As idades variam de 29 a 48 anos, e o tempo de serviço, de três a 35 anos. 
Tabela 1. Distribuição dos participantes de entrevistas por funções que desempenham

\begin{tabular}{cc}
\hline Participantes envolvidos & $\boldsymbol{n}$ \\
\hline Gestores do IFP de Chongoene & 2 \\
Formadores de professores primários e de educadores de adultos & 14 \\
\hline TOTAL DE PARTICIPANTES & $\mathbf{1 6}$ \\
\hline
\end{tabular}

Fonte: Elaborada pela pesquisadora

Um dos grandes desafios que os participantes deste estudo enfrentam no processo de ensino e aprendizagem é a falta de formação profissional específica para a função de formador de professores, como se pode inferir da colocação que se segue:

"Não passámos por uma instituição direccionada à formação de formadores para os IFP, apenas por aquelas outras formações para professores primários e secundários (FP2)". E mais adiante a formadora em ensino bilingue rematou:

"Não existe formação específica para formadores, eu não tive nenhum curso como formadora em ensino bilingue (FP4)", secundado por um outro participante nos termos seguintes: "Quando chegamos aqui temos que nos adaptar, sermos criativos, saber como preparar alguém para ir ensinar crianças ou adultos (FP12)".

Um outro desafio não menos importante é a necessidade urgente de especialização dos formadores, como se pode inferir no seguinte comentário:

Julgo que a questão de especialização é o que se pretende num futuro não distante, especialização porque tomando em consideração que o professor do ensino primário lecciona português, matemática e ciências sociais...isso torna-se impossível garantir-se qualidade exigida. Por outro lado, formar alguém para ensinar a crianças e ao mesmo tempo ensinar adultos é um pouco desastroso...mas na situaçãoo em que Moçambique está é o que vai ter que ser feito... aqui precisamos de alguém que tem ser um super homem ou um super professor para atender isso tudo (FP14).

É neste ambiente desafiante que os participantes desta pesquisa inicaram em 2019 com a implementação do novo modelo de formação de professores em Moçambique.

O objectivo do novo modelo de formação de professores $\left(12^{\mathrm{a}}+3\right)$ é produzir professores dotados de uma formação integrada por saberes plurais construídos, capazes de trabalhar com as pessoas de todas as idades, desde o ensino primário à educação de adultos.

Os participantes deste estudo são unânimes em afirmar que, apesar de o novo modelo ser bem-vindo, apresenta certas lacunas cuja solução é urgente, designadamente: (i) 
grande parte dos conteúdos está mais virada para o ensino primário; (ii) o modelo dispõe de apenas um semestre para o tratamento das questões relacionadas com a educação de adultos; (iii) falta de manuais para a preparação adequada de educadores de adultos; (iv) os formandos realizam o seu estágio em escolas do ensino primário. Entretanto, as especificidades da profissionalidade do formador de professores primários e de educadores de adultos do IFP de Chongoene emergiram nos dados e constituíram se em unidades de análise às suas percepções, expectativas e motivações. Assim, foram seleccionadas e definidas as seguintes categorias de respostas:

Tabela 2. Categorias identificadas e respectivas unidades de registo

\begin{tabular}{|c|c|c|c|c|}
\hline \multirow[t]{2}{*}{ Código } & \multirow[t]{2}{*}{ Categorias } & \multicolumn{2}{|c|}{$\begin{array}{l}\text { Unidades de } \\
\text { Registo }\end{array}$} & \multirow[t]{2}{*}{ Fontes } \\
\hline & & $n$ & $f$ & \\
\hline C1 & Motivação & 54 & $21 \%$ & 29 \\
\hline C2 & Estatuto de capacidade profissional a dominar & 40 & $15 \%$ & 24 \\
\hline C3 & Centralidade na prática docente & 37 & $14 \%$ & 24 \\
\hline C4 & Necessidade da planificação da prática docente & 25 & $10 \%$ & 14 \\
\hline C5 & Espírito crítico sensível e construtivo & 23 & $9 \%$ & 13 \\
\hline C6 & $\begin{array}{l}\text { Reconhecimento de todo o esforço e aquisição de } \\
\text { aprendizagens }\end{array}$ & 20 & $8 \%$ & 13 \\
\hline C7 & Auto-avaliação & 18 & $7 \%$ & 6 \\
\hline C8 & Compreensão dos objectivos e critérios & 16 & $6 \%$ & 8 \\
\hline C9 & Apoio à melhoria do trabalho do aluno & 14 & $5 \%$ & 16 \\
\hline C10 & Consideração da(s) forma(s) como os alunos aprendem & 12 & $5 \%$ & 15 \\
\hline & TOTAL & 259 & $100 \%$ & N/A \\
\hline
\end{tabular}

Fonte: Elaborada pela pesquisadora

Para se efectuar a análise de conteúdo defendida por Bardin (1979), foram estabelecidas dez categorias prévias nas quais couberam 259 Unidades de Registo (UR). No Gráfico 1, pode- se observar as categorias e as respectivas unidades de registo, arrumadas em ordem decrescente do número de unidades de registo.

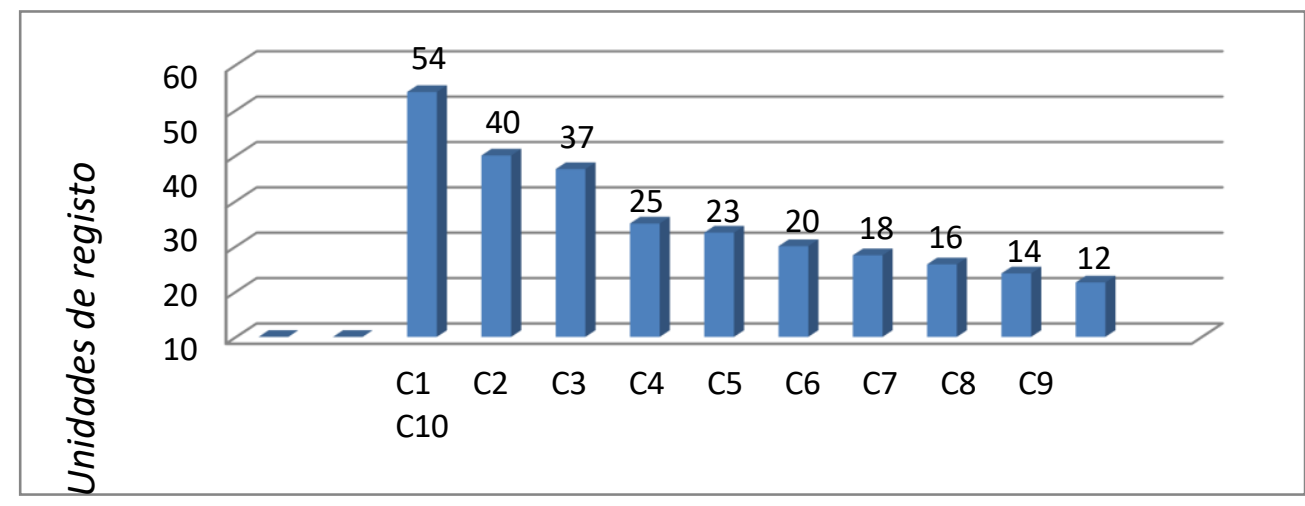

Gráfico 1. Categorias em função das unidades de registo - Fonte: Elaborado pela pesquisadora 
Os interpretativistas estabelecem diferença epistemológica (is it knowable ? $^{1}$ ) fundamental entre ciências sociais e ciências naturais. A perspectiva epistemológica interpretativista sustenta que "a realidade social não é apenas para ser observada, mas antes interpretada" (Corbetta, 2003, p.21). Neste contexto, em seguida procura-se, resumidamente, descrever cada uma destas categorias.

\subsection{Categoria "Motivação"}

A motivação para ensinar assume um carácter complexo que a impede de ser encarada apenas como um pretexto para o facilitismo; obrigando a que a tónica assente em dois aspectos cruciais do acto de ensinar: o gosto pela aprendizagem efectiva dos aprendentes e a capacidade de ensinar efectivamente.

A motivação tem um papel processual por se assumir como um caminho indissociável do processo de ensino e aprendizagem: o percurso académico do aluno.

Por isso mesmo, a motivação faz uso daquela que é uma das principais ferramentas da metodologia da avaliação formativa: o feedback - acompanhamento sistémico do aluno apoiado com comentários num diálogo permanente e aberto de forma a detectar os progressos e falhas dos aprendentes, conforme relato a seguir: "[...]Treinar o formando em quase todos os aspectos...quer nos trabalhos de pesquisa, seminários, saber ser e estar (FP1)".

Segundo Locke (1984), a satisfação no trabalho está associada a uma série de consequências organizacionais e esta série de possíveis consequências e reacções é muito variada e complexa, pois a satisfação no trabalho é seguramente uma resposta emocional, que se afasta, em larga medida, não só da certeza de uma aprendizagem real e efectiva de todos os conteúdos ensinados, mas também da Motivação Intrínseca que a médio e longo prazo tem a capacidade de promover a aprendizagem e o gosto/motivação de aprender "na troca permanente de experiências com colegas".

${ }^{1}$ É reconhecível? (livre tradução) 
Respondendo a uma provocação nossa sobre se pudesse deixaria de trabalhar nesta modalidade de ensino, mais de $80 \%$ dos participantes desta pesquisa forma unânimes em afirmar que "se sentem muito bem a trabalhar com esta modalidade de ensino e têm gosto de pôr alguém a trabalhar para o bem estar das crianças, dos adultos e para a comunidade e sociedade no geral".

\subsection{Categoria "Estatuto de Capacidade Profissional a Dominar"}

A formação e o desenvolvimento profissional dos professores tem-se revelado, aliás, um tema algo polémico um pouco por todo o mundo, sendo alvo de críticas constantes, como é disso exemplo o trabalho de Levine (2006), que relançou uma forte polémica por, de forma muito

clara, ter demonstrado que o trabalho do professor obedece, nos dias de hoje, a critérios e obrigações de complexidade, exigência e rigor técnico que não se compadecem com as práticas desactualizadas que ainda informam a praxis de muitos educadores da actualidade:

(...) Os professores de hoje precisam de saber e serem capazes de fazer coisas que seus antecessores não faziam. Eles devem estar preparados para educar todos os seus alunos de forma a atingir os melhores resultados de sua história. Este é um trabalho fundamentalmente diferente das gerações passadas de professores (Levine, 2006, p.11).

Stiggins (2008) critica também o sistema de formação e acompanhamento profissional dos professores, apontando o que, em sua opinião, constitui uma falha grave: a ausência, ao longo de muitos anos, de metodologias de capacitação dos professores para avaliarem mais e melhor. O relato que se segue é bem elucidativo desta realidade "há falta de professores nas cidades, nos distritos e nas localidades; temos professores que têm duas turmas e dão aulas de manhã e à tarde e em algumas escolas funcionam três turnos (FP1)".

\subsection{Categoria "Centralidade na Prática Docente"}

Todo o trabalho do docente, o que implica necessariamente toda a sua actividade em contexto de sala de aula, pode representar um acto avaliativo, uma decisão, como afirma Stiggins (2008), uma reflexão, uma acção pensada para influenciar o processo de ensino e aprendizagem de cada aprendente ou grupo na turma. O conhecimento prático, isto é, a 
"cultura docente em acção", resulta da articulação de saberes disciplinares e curriculares, da formação profissional e saberes experienciais (Tardif, 2002, citado em Borges, 2014, p.42), conforme destacado a seguir: "Apresentei proposta de alastramento de tempo de abordagem dos conteúdos, de módulos para disciplinas semestrais...para se evitar a descontinuidade do currículo" (FP3)".

\subsection{Categoria "Necessidade da Planificação da Prática Docente”}

Nem todos os professores participantes deste estudo planificam da mesma forma e com o mesmo fim. Contudo, pode-se inferir que a planificação da prática docente garante a gestão de sala de aula e permite que estes se sintam mais seguros, e com menos incertezas. Para planificar, é preciso que o professor perceba a dinâmica exigente dentro da sala de aula, para saber o que vai fazer, porquê e como vai proceder para saber se os alunos aprenderam. Neste sentido, os métodos e estratégias de ensino devem promover permanentemente a aprendizagem, a colaboração e troca de experiências entre os aprendentes.

A planificação da prática docente funciona, assim, como instrumento didáctico para a realização dos objectivos definidos no currículo. Este ponto de vista parece ser ilustrado na colocação que segue: "deve- se ensinar conteúdos que resolvem os problemas dos adultos, produzindo materiais adequados...de forma a munir o formando de princípiosa dequados de psicopedagogia e andragogia" (FP15)".

\subsection{Categoria "Espírito Crítico Sensível e Construtivo"}

O professor deve incutir no aprendente a ideia de que é possível melhorar os seus resultados anteriores, promovendo assim tentativas de sucesso que vão ao encontro das expectativas do aprendente, alvo de comentários estruturantes ao seu trabalho. Os professores conseguem assim ultrapassar, em certa medida, a exclusividade dos juízos de valor esporádicos e quantitativos, passando a focar o ensino na aprendizagem. $O$ aprendente deixa de ser julgado e conotado com uma avaliação numérica e contabilística, sem passar primeiro por todo um processo de acompanhamento necessário ao reforço da auto-confiança no âmbito do domínio efectivo dos conteúdos curriculares.

Nesta categoria os participantes deste estudo encorajam os seus aprendentes a organizarem- se em círculos de aprendizagem, a desenvolver o espírito colaborativo e de 
entre-ajuda para se alcançar o máximo dos resultados. Desta forma, o processo de ensino e aprendizagem é amplificado como resultado das suas interacções serem multiplicadas por diferentes pessoas em muitos contextos. Neste contexto, um comentário/ feedback sensível e construtivo é um comentário dirigido ao trabalho do aprendente, evitando juízos de valor sobre o próprio aprendente e entre os colegas do grupo na turma. Deve ser claro e conciso, acompanhado de exemplos de bons trabalhos, paradigmas do seu próprio progresso, segmentado em tão pequenas fases quanto as necessárias, até ao cumprimento dos objectivos mais latos das aprendizagens dispostas no programa curricular.

O comentário estruturante e sistémico é responsável por desenvolver nos aprendentes a capacidade de compreenderem o seu próprio percurso de ensino e os seus critérios de aprendizagem, aos quais não são alheios de todo, o que pressupõe proporcionar um ambiente de aprendizagem suficientemente profícuo e estimulante que substitua a tradição das "recompensas" - uma nota por um teste (Black \& William, 2006), por mecanismos que incentivem a aprendizagem, motivando-a e agindo sobre ela, onde e quando esta acontece - em contexto de sala de aula, todos os dias.

\subsection{Categoria "Reconhecimento de todo o Esforço e Aquisição de Aprendizagens"}

O reconhecimento do esforço de cada aprendente deve basear-se na constatação do progresso do mesmo, rumo ao domínio dos pressupostos curriculares. O reforço e acompanhamento dos aprendentes deve proporcionar não só os elogios relativos aos objectivos já alcançados, mas também, orientações necessárias à melhoria e correcção dos insucessos e falhas. Através da accão-reflexão desenvolve-se o pensamento crítico, promove-se a comunicação e garante-se uma educação comprometida com a humanização. Neste processo, professores e aprendentes interagem entre si, em debate aberto e profundo que culmina com a (re)construção do(s) plano(s) de aula, adequandoo(s) ao contexto e experiências de vida dos aprendentes, "permitindo que o formando seja capaz de produzir seu próprio conhecimento".

\subsection{Categoria "Auto-avaliação"}

A capacidade de auto-avaliação, desdobramento pedagógico do preceito filosófico "conhece- te a ti mesmo", é um dos tópicos mais transversais da auto-estima e gera 
determinação e confiança em suas accções educativas. A capacidade de auto-avaliação, dirigida preferencialmente a objectivos curriculares de pequena dimensão, deve estenderse ao longo do percurso escolar do aprendente, de forma a segmentar as grandes temáticas em secções mais pequenas e fáceis de ensinar, permitindo assim acompanhar o aprendente, revelando exemplos de bom e mau trabalho e incentivando o desenvolvimento da sua capacidade de fundamentação - crucial para que possa avaliar o seu trabalho antes de o revelar ao professor. A autoavaliação gera a reflexão sobre os conteúdos currilares e/ou estratégias para agir cada vez melhor.

\subsection{Categoria "Compreensão dos Objectivos e Critérios"}

A percepção do que são os objectivos e os critérios de avaliação constitui um factor determinante do sucesso escolar dos aprendentes. O domínio dos princípios da Andragogia permite ao formador definir claramente os objectivos da aprendizagem e os resultados esperados. Contudo, há que ter sempre em conta outros factores a identificar nos espaços de aprendizagem, que interferem no processo de aprender, como por exemplo, as diferenças próprias de cada um, as diferenças de contextos, metas e propósitos de aprendizagem.

A explicitação, em contexto prático de sala de aula, dos objectivos da aprendizagem e dos critérios de avaliação da mesma não se confina à explicação da melhor forma de conseguir os melhores resultados nos momentos de avaliação.

Neste processo, professores e aprendentes reflectem sobre a sua realidade, sobre o que sabem e não sabem, para construir novos saberes como sujeitos conscientes e comunicativos, discutem como estudar e trabalhar os conteúdos e as aprendizagens, orientando todo este processo através do diálogo. A dialogicidade catalisa o pensamento crítico, promove a comunicação e garante uma educação comprometida com a humanização (Soares \& Pedroso, 2013).

\subsection{Categoria "Apoio à Melhoria do Trabalho do Aluno"}

Nesta categoria cabe a relação que os professores desenvolvem com os seus aprendentes, o empenho na planificação rigorosa das aulas e disponibilização de recursos e materiais didácticos de forma a minimizar as dificuldades e/ou barreiras do processo de ensino e aprendizagem. Os participantes deste estudo deixaram evidente que: 
[...]se estimula nos aprendentes o autodidactismo, a capacidade de autoavaliação e autocrítica, as habilidades profissionais, a capacidade de trabalhar em equipas. E, sobretudo, enfatiza-se a responsabilidade pessoal pela própria aprendizagem e a necessidade e capacitação para a aprendizagem continuada ao longo da vida; Incentiva-se os aprendentes a promoverem encontros entre si bem como com colegas do IFP mais próximo²...treinamento do formando na habilidade de pesquisa, aplicação de métodos participativos, aceitação positiva do aluno, buscando um ensino mais humanizado.

\subsection{Categoria "Consideração da(s) Forma(s) como os Alunos Aprendem"}

Esta categoria refere-se à necessidade, por parte dos professores, de procurarem "conhecer seus educandos, suas características, suas culturas, suas expectativas, além de suas necessidades de aprendizagem" (Soares \& Pedroso, 2013, p.4), construindo "uma postura dialógica e dialéctica" (Freire, 1992, citado em Soares \& Pedroso, 2013, p.4).

De facto, "ser educador exige uma postura aberta e dialógica, de comunhão em relação ao contexto no qual cada educando está inserido e aos valores que trazem consigo" (Soares \& Pedroso, 2013, pp.7-8). Deste modo, os professores viram colaboradores da produção do saber e compreendem que ensinar significa criar possibilidades para a construção do conhecimento, contribuindo para a autonomização do trabalho do aprendente, que passa a ser co-responsável pela sua aprendizagem.

\section{CONSIDERAÇÕES FINAIS}

Este estudo, de carácter exploratório e descritivo, foi desenvolvido com recurso ao paradigma interpretativista, seguindo uma abordagem qualitativa, integrando 16 participantes do IFP de Chongoene. Desta forma, importa salientar que os resultados por nós obtidos não se podem generalizar a outros contextos formativos e geográficos. Esperamos, no entanto, que os mesmos contribuam para a compreensão das dinâmicas pedagógicas, em particular no que à construção da profissionalidade dos formadores de professores primários e de educadores de adultos se refere.

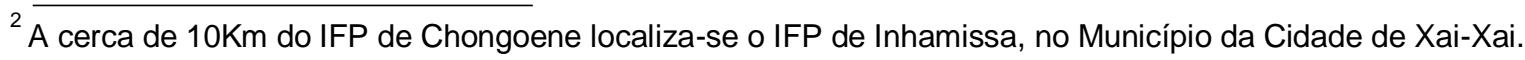


Uma primeira conclusão que se pode tirar dos dados obtidos com esta pesquisa é a de que, a profissionalidade docente revela-se pela constante mobilização de saberes diversos para identificar e resolver problemas quotidianos marcados pela incerteza, imbuídos por uma forte motivação intrínseca dos participantes deste estudo. Verificámos que na dimensão institucional os participantes deste estudo enfrentam a falta de formação profissional específica para a função de formador de professores, enquanto que na dimensão pedagógica clamam pela necessidade urgente de sua especialização. Percebemos que eles consideram fundamental estar em constante formação para o seu desenvolvimento profissional de forma a melhorar o processo de ensino com o objectivo de dar resposta ao novo modelo de formação de professores, levando até aos formandos, aprendizagens efectivas. De facto, e alinhando com Gorzoni e Davis (2017, p.16), "Grande parte dos autores coloca ênfase na construção de competências e no desenvolvimento de habilidades próprias ao ato de ensinar, adquiridas nas formações e nas experiências de trabalho do professor". Contudo, esta pesquisa sugere-nos ainda que salários baixos, ausência de socialização profissional, desgaste físico e, particularmente, a falta de reconhecimento da actividade profissional são alguns dos factores desmotivadores do desenvolvimento profissional dos formadores de professores primários e de educadores de adultos, chegando a gerar grandes níveis de ansiedade e depressão. Estes e outros factores são inibidores da constituição da profissionalidade do formador de professores primários e de educadores de adultos do IFP de Chongoene.

Por acreditarmos que este trabalho trouxe relevantes contribuições para a construção da profissionalidade dos formadores de professores primários e de educadores de adultos do IFP de Chongoene, propomos a continuidade das pesquisas sobre este conceito nos seguintes aspectos: (i) Desenvolvimento de uma ferramenta de gestão de processos e pessoas para instituições de formação de professores, aliando a gestão pedagógica, tecnológica e administrativa; (ii) Contribuição da linguística no desenvolvimento dos materiais didácticos e no atendimento aos formandos; (iii) Desenvolvimento de metodologias de avaliação de processos e de resultados do trabalho quotidiano do formador do IFP de Chongoene. Há muito que pesquisar e muitos vazios ainda por serem preenchidos na construção da profissionalidade dos participantes desta pesquisa. 


\section{REFERÊNCIAS}

Ambrosetti, N. B., \& Almeida, P. C. A. (2009). Profissionalidade docente: uma análise a partir das relacões constituintes entre os professores e a escola. Revista Brasileira de Estudos Pedagógicos, Brasilia, $90(226)$, 592-608.

André, M. E. D., \& Placco, V. N. (2007). Processos psicossociais na formação de professores: um campo de pesquisas em Psicologia da Educação. Contrapontos, 7(2), 339-346.

Bardin, I. (1979). Análise de conteúdo. Lisboa: Edições 70.

Black, P., \& Wiliam, B. (2006). Assessment for Learning in the classroom. In J. Gardner (Ed.). Assessment and Learning. (pp. 9-25) London: Sage.

Borges, M. L. (2014). Profissionalidade docente: da prática à praxis. Investigar em Educação, II a Série(2) Chontreras, J. (2012). A autonomia de professores. Tradução de Sandra Trabucco Venézuela. (2 ${ }^{\underline{a}}$ ed). São Paulo: Cortez. Corbetta, P. (2003). Social Research: Theory, Methods and Techniques. Translated by Bernard Patrick. (1st
ed).

London: SAGE Publications.

Creswell, J. W. (2007). Qualitative Inquiry \& Research Design: choosing among five approaches. (2nd ed).

Thousand Oaks: Sage.

Despacho Ministerial ํo 263/GM/MINEDH/2015, de 09 de Outubro, que extingue os os Institutos de Formação de Educadores de Adultos.

Diploma Ministerial 180/2010, de 3 de Novembro. Cria os Institutos de Formaccão de Educadores de Adultos Freire, P. (2013). Pedagogia do Oprimido. [recurso eletrônico]. (1ํㅡㄹ ed), Rio de Janeiro: Edições Paz e Terra.

Gimeno Sacristán, J.(1995). Consciência e ação sobre a prática como libertação profissional dos professores. In: Nóvoa, A. (Ed.). Profissão professor (pp. 63-92). (2ª ed). Porto: Porto.

Gorzoni, S., \& Davis, C. (2017) O Conceito de Profissionalidade Docente nos Estudos mais Recentes. Cadernos de Pesquisa, 47(166), 1396-1413.

Habermas, J. (1984). The theory of communicative action, Vol. 1, Reason and the rationalization of society.

Boston: Beacon Press.

Knowles, M. S. (2005). The Adult Learner: The Definitive Classic in Adult Education and Human Resource Development. (6th ed). San Diego, Califórnia, USA: Elsevier.

Levine, A. (2006). Educating School Teachers. Washington, DC: The Education Schools Project. Libâneo, J.

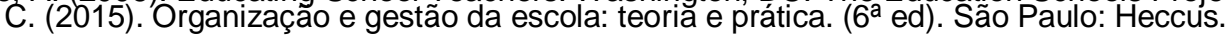

Locke, E. L. (1984). Job satisfaction. In: M. Gruneberg \& T. Wall (Eds.). Socialpsychology and organizational behavior. New York: John Wiley \& Sons.

Miles, M., \& Huberman, M. (1994). Qualitative data analyses. London: Sage.

Morgado, J. C. (2011), Identidade e profissionalidade docente: sentidos e (im)possibilidades. Ensaio: Avaliação e Políticas Públicas Educacionais, Rio de Janeiro, 19(73), 793-812.

Preti, D. (1999). O discurso oral culto. (2ª ed). São Paulo: Humanitas Publicações - FFLCH/USP.

Ramalho, B. L., Nuñez, I. B., \& Gauthier, C. (2004). Formar o professor, profissionalizar o ensino: perspectivas e desafios. (2⿺ ed). Porto Alegre: Sulina.

Roldão, M.C. (2005). Profissionalidade docente em análise: especificidades dos ensinos superior e não superior.

Nuances: Estudos Sobre Educação, 12(13), 105-126.

Soares,L. J. G., \& Pedroso, A.P. F. (2013). Dialogicidade e a Formação de Educadores na EJA: As Contribuições de Paulo Freire. ETD - Educ. temat. digit., 15(2), 250-263. ISSN 1676-2592.

Stake R. E. (2009). A arte de investigacão com estudo de caso. (2 $2^{\mathrm{a}}$ ed). Lisboa: Fundacão Calouste Gulbenkian. Stiggins, R. (2008). Student-involved classroom assessment. (5th ed). Columbus, Ohio: Merrill Prentice Hall. 